\title{
Market Size, Product Differentiation and Bidding for New Varieties ${ }^{1}$
}

\author{
Jie $\mathrm{Ma}^{2}$ \\ University of International Business and Economics \\ Ian Wooton ${ }^{3}$ \\ University of Strathclyde, CEPR and CESifo
}

24 June 2019

\footnotetext{
${ }^{1}$ We wish to thank the Editor-in-Chief, Ronald Davies, two anonymous referees, Giuseppe De Feo, Ben Ferrett, Armando Pires, Pascalis Raimondos, Martin Richardson and Maurizio Zanardi for their helpful comments and suggestions. Jie Ma thanks Wei Du and Chao Liu for their excellent research assistance. The usual disclaimer applies.

${ }^{2}$ Corresponding author. Department of International Trade, School of International Trade and Economics, University of International Business and Economics, No. 10 Huixin Dongjie, Chaoyang District, Beijing 100029, China; e-mail: jie.ma@uibe.edu.cn.

${ }^{3}$ Department of Economics, Strathclyde Business School, 199 Cathedral Street, Glasgow G4 0QU, United Kingdom; e-mail: ian.wooton@strath.ac.uk.
} 


\begin{abstract}
We analyse a firm's investment decision in a regional economy composed of two countries. The firm already manufactures a horizontally differentiated good in the region and we determine the firm's equilibrium location choice for the new good and the welfare consequences of fiscal competition between the two countries. We find that the firm's location decision is efficient. Fiscal competition does not affect the location of production but merely redistributes rents between the firm and the taxpayers of the host country. As far as we know, the tax competition literature has not previously addressed the issue of product differentiation.
\end{abstract}

Keywords: FDI, import substitution, market size, MNEs, product differentiation JEL classifications: F21, F23, H21, H25, L22 


\section{Introduction}

International policy competition to attract foreign direct investment (hereafter FDI) has become commonplace in the past thirty years and seems to be on the rise. ${ }^{1}$ Firms care about the location of their production facilities, wanting to minimize their production costs while being close to their major consumer markets. For their part, national governments prefer local manufacturing over imports, as this provides domestic jobs and demand for local services as well as cheaper consumer products. Given this preference for local production, a government may offer incentives in order to persuade firms to locate their production facilities within its territory. When there is more than one candidate country as host of the FDI, international fiscal competition may arise to attract the manufacturing facilities.

In recent years, a number of papers have been written examining different aspects of international competition to influence the location of production. We contribute to this growing literature by arguing that product differentiation, a factor that has been largely overlooked, may affect the FDI location choice, investment policy and national welfare in interesting ways. This paper considers the choice of a monopolistic firm as to whether it should invest in the introduction of a second, horizontally differentiated variety of a good that it currently produces and sells in a two-country regional economy. Location matters because the firm has to pay trade costs in selling to its foreign market. We assume that one country is larger than the other and consequently, in line with the established literature, the production of the original variety takes place in this larger nation. The firm's decision, then, is not just whether or not to introduce the new variety, but where to produce this variety.

An example of a firm that has chosen to divide its portfolio of varieties across a region in the face of (anticipated) trade costs is Jaguar Land Rover (JLR). This firm, having previously concentrated all of its European production in the UK, has built a factory in Slovakia where it will concentrate the production of its Discovery and new Defender models. This has occurred at a time of uncertainty regarding the UK's future relationship with the EU in light of the Brexit referendum. While their future relationship is uncertain, most scenarios predict an increase in the costs of trading products between

\footnotetext{
${ }^{1}$ Overviews of competition for FDI can be found in, e.g. UNCTAD (1996), Oman (2000), Charlton (2003) and Barba Navaretti and Venables (2004).
} 
the UK and continental Europe. In anticipation of this, our model suggests that firms may choose to split their product lines over factories in more than one location. ${ }^{2}$

We examine the factors influencing the firm's choice and, in particular, how fiscal competition between the two nations to attract this second new FDI affects the outcome in equilibrium. In this setting, we define these factors to be: a market-size effect, a product-differentiation effect, and an import-substitution effect. Given the existence of intra-regional trade costs, all else equal, the firm has an incentive to invest in the larger country in order to save on these trade costs, reflecting the market-size effect. The product-differentiation effect concerns the firm's increasing incentive to co-locate the production of its existing and new varieties as the two varieties become more differentiated. Finally, the import-substitution effect arises from a country's preference for locally produced goods over imported goods, since the price of the former is cheaper than that of the latter. Our results show that the firm's location choice is determined exclusively by the interaction between the market-size effect and the product-differentiation effect, both of which (as defined) work to attract the FDI to the larger market. Given the existence of intra-regional trade costs, the firm seeks to establish its new production facility in the location that minimizes these expenses across both varieties of its product. Thus one or both of these effects must be weak if the smaller country is to have the opportunity of attracting the FDI. If, for instance, the product-differentiation effect is very weak and the varieties are therefore close substitutes for one another, then the firm will have an incentive to spatially separate its two plants. If, instead, the varieties are strongly differentiated from each other, the firm will locate the production of both varieties in the country that provides the larger domestic market.

When we consider the role of fiscal competition in influencing the location decision of the firm, we find that it is entirely impotent. Thus while the import-substitution effect creates an incentive for the rival governments to make bids in order to attract the FDI, in equilibrium it has no effect on the choice of location. Furthermore, the location decision made independently by the MNE is efficient, such that the policy competition merely results in transfers between the host of the FDI and the MNE. With respect to the distribution effects from the FDI, the competition for FDI may Pareto weakly improve the national welfare of the competing countries when the host nation's geographic advantage is sufficiently strong that it is able to tax the MNE in equilibrium.

\footnotetext{
${ }^{2}$ See https://www.ft.com/content/f2c6e930-6d7f-11e8-852d-d8b934ff5ffa for further details.
} 
The existing literature has addressed the market-size and import-substitution effects but, as far as we know, the product-differentiation effect that we identify in this paper is new to the literature of tax competition with imperfectly competitive markets.

Our analysis has interesting implications for international investment policy. There has been a hot policy debate about the possible effects on the competing countries of their engaging in a "bidding war" for FDI. The opponents of FDI competition argue that the competition results in a pure waste of the competing countries' resources, and may weaken their public finances and distort the location of investment. The advocates of FDI competition argue against tax harmonization since it is, effectively, a governmental tax and spending cartel, which is every bit as objectionable as a private cartel. Our analysis suggests that although the MNE's location choice is always efficient, FDI competition can erode the welfare of competing countries when neither country has an overwhelming edge over its rival in the FDI competition and the winner has to pay a subsidy in equilibrium to the MNE in order to attract the FDI. This might lead to a call for international cooperation in investment policy. ${ }^{3}$ However, when the winning country has an advantage in FDI competition that cannot be matched by its rival, there is no need for tax harmonization as the firm pays a tax to the host country in equilibrium.

\section{Related literature}

With strong scale economies, firms will choose to concentrate their production of any variety of a good in a single location, servicing consumers in other markets through exports. In the face of trade costs, the choice of location takes on greater importance, as firms will find it more profitable to produce in larger, less competitive markets compared to producing in a smaller market in the presence of domestic rivals.

In Brander and Krugman (1983), costly trade between two imperfectly competitive firms can arise, despite them both producing an identical product. This paper became the benchmark for a vast literature analysing the location of regional economic activity in the presence of trade costs, scale economies, market-size asymmetries, and government policies. Our paper contributes to this literature by considering the location choice of a multiproduct firm in such a regional setting and whether this is affected

\footnotetext{
${ }^{3}$ Also see UNCTAD (2012) and UNCTAD (2015).
} 
by international competition to attract the FDI.

Haufler and Wooton (1999) focus on differences in market size in order to determine which country will succeed in attracting the FDI of a single-product firm. They examine how the investment choice is influenced by intergovernmental competition to attract the FDI. They find that the larger country always wins and, if there is a sufficiently large differential in the sizes of the two countries, the larger country may attract the FDI in equilibrium with a positive tax, despite the smaller, unsuccessful country being willing to subsidize the firm's investment.

Baldwin and Ottaviano (2001) show that multiproduct firms, which produce horizontally differentiated products, may simultaneously engage in intraindustry FDI and intraindustry trade across two identical countries. They extend the Brander and Krugman framework of two identical countries, each home to a single firm, by assuming that each firm produces two imperfectly competitive varieties of the good. They then examine the incentives facing firms to produce one of their goods in the foreign market, resulting in two-way FDI and countries importing the foreign-produced manufactures of their home firms. The reason for the cross-hauling FDI in Baldwin and Ottaviano is that multiproduct firms use trade costs to reduce inter-variety competition by placing production of some varieties abroad. Product differentiation also plays a major role in our model but, unlike Baldwin and Ottaviano and in line with Haufler and Wooton, the host countries are not identical and the governments of these countries compete to attract the FDI. The single firm in our model seeks to maximize its global profits by the choice of the location of its second production plant where, as in Baldwin and Ottaviano, there is an incentive to separate its product varieties spatially when they are close substitutes.

We want to emphasize several aspects of our results. First and unlike Haufler and Wooton, the smaller country has a chance to win the FDI competition. Second, a sufficiently large differential in the sizes of the two countries cannot guarantee that the larger country will win the FDI while charging a positive tax. This is because, in addition to the market-size effect, the product-differentiation effect also plays a role in the FDI competition. Third, our result that fiscal competition does not change FDI location choice is in line with both Haufler and Wooton (1999) and Ma (2013). In contrast, Barros and Cabral (2000), Fumagalli (2003), Bjorvatn and Eckel (2006) and Ma (2017) all show situations where FDI competition may change MNEs' location 
choices. Finally, although Haufler and Wooton (1999) do not discuss the welfare effects of FDI competition, their analysis implies that the FDI location choice is consistent with total-surplus maximisation. See also Barros and Cabral (2000), Bjorvatn and Eckel (2006), Ma (2013), and Ma (2017).

Ferrett and Wooton (2010) build on the Haufler and Wooton framework by asking how the equilibrium outcome is changed when the countries are competing for FDI from two firms producing a homogeneous good. If both firms invest in the same country, they experience more competition than if the firms were to spatially separate their FDI. In this latter case, the firm investing in the smaller country is at a disadvantage. If the size difference between the two countries is sufficiently great, the firms will accept the more competitive market environment arising from both investing in the larger country. In our paper, we treat the entry of the first plant as exogenous and consider only the location choice of the new investment, while we also move away from the assumption that the two goods are perfect substitutes.

Our contribution to these two streams of the literature is in investigating the interactions between product differentiation and market size. We examine the location choice for a firm's new production facility, when goods are imperfect substitutes and potential host countries differ in size. The single firm in our model internalizes the potential competition between the two varieties it produces, choosing where (and if) to make its investment and whether this decision is influenced by international competition to attract the FDI.

Bjorvatn and Eckel (2006) also have an asymmetry in country size but, in addition, consider the implications of there being a domestic firm already producing in the larger country. The presence of this incumbent firm makes the domestic market of the larger country more competitive for the investing firm and may lead the latter to choose to locate its FDI in the smaller country. In this setting, international policy competition can result in a more efficient location choice by the firm.

The remainder of the paper proceeds as follows. Section 2 sets out our model in which a firm introduces a second variety of its good to the region. Sections 3 and 4 examine the firm's location choice without and with fiscal competition for FDI, respectively. In Section 5, we discuss the welfare implications of the fiscal competition. In the final section, we summarize our results and consider further implications of our model. ${ }^{4}$

\footnotetext{
${ }^{4}$ Some technical discussions can be found in the Appendix.
} 


\section{The model}

We investigate investment decisions in a two-country regional setting, where a firm from the rest of the world produces goods with increasing returns to scale for consumers in both countries. International trade is costly, such that the firm faces a higher cost in supplying consumers through exports as compared to domestic production.

The two countries in the region are indexed by $i \in\{A, B\}$. The market size of $A$ is normalized to 1 while $N$ is the market size of country $B$, where $N \geq 1 .^{5}$ An MNE owned by agents outside of the region can produce two varieties of the consumption good, indexed by $j, k \in\{1,2\}$. Let $p_{j}^{i}$ denote the market price of variety $j$ in country $i$, while $q_{j}^{i}$ is the corresponding per-capita quantity demanded of variety $j$ in country $i$. Given our assumptions about the sizes of the two countries, the total demand for variety $j$ in country $A$ is $Q_{j}^{A}=q_{j}^{A}$, while the total demand for that variety in country $B$ is $Q_{j}^{B}=N q_{j}^{B}$.

Initially only a single variety, good 1, is available as the result of past FDI in the region by the MNE. In this situation, the inverse demand of a representative consumer in country $i$ for this variety is given by $p_{1}^{i}=1-q_{1}^{i}$. The marginal cost of production is assumed to be the same in both countries and, for simplicity, set at zero. However, exports of the good incur a transport cost of $\tau>0$ per unit. On that basis, we anticipate that the MNE will have established its production plant for the first variety in the larger country in order to serve the regional market. ${ }^{6}$ We further assume that sunk costs of investment are sufficiently large that the firm will not choose to move the production of this variety at any point.

The MNE faces the decision as to whether or not it should introduce to the region a new variety of the product, good 2 , that is horizontally differentiated from good 1 , the existing variety. Its decision to make the investment will depend upon a number of factors, including production and trade costs, the strength of demand for the good, consumers' love of variety, and the degree to which the two varieties are different from one another. If the new variety is made available in the regional market, we assume

\footnotetext{
${ }^{5} \mathrm{~N}$ measures the market size of country $B$ relative to that of country $A$.

${ }^{6}$ This supposition is in line with existing models, e.g. Haufler and Wooton (1999).
} 
that the inverse demand for variety $j$ by a representative consumer in country $i$ is: ${ }^{7}$

$$
p_{j}^{i}=1-q_{j}^{i}-b q_{k}^{i},
$$

where $j \neq k$. The parameter $b \in[0,1]$ measures the degree of product differentiation. Clearly, as $b$ approaches unity, the two varieties become even closer substitutes for each other. In contrast, when $b$ falls, the two varieties become increasingly differentiated such that they become distinct goods at $b=0$.

The cost of importing goods from outside of the region is assumed to be prohibitive. Hence, if the MNE wishes to introduce a new variety into the region, it must make an investment in one of the two countries. ${ }^{8}$ When the MNE decides to invest in country $A$, it has to pay a fixed cost to establish a new plant to produce the new variety. If the firm wishes to co-locate production and manufacture both varieties in country $B$, it can do so by paying a fixed cost to upgrade its existing plant. For the sake of simplicity, we assume that these fixed costs are the same and equal to $f>0 .{ }^{9}$ Exporting variety 2 incurs the same cost of $\tau$ per unit. We assume that the trade cost is sufficiently small that:

$$
\tau<(1-b) .
$$

This assumption guarantees that the MNE should be able to service both countries' demands for the two varieties irrespective of its location choice for the new investment. The fixed cost of FDI and the trade cost are the only costs that the MNE faces in order to set up and supply both varieties in the regional market. There are two asymmetries already in the model that will affect the choice of location of the new variety: the countries differ in size; while the MNE's production of the first variety is already located in the larger country.

The incentives facing the agents in the model are as follows. The MNE receives its profits net of any tax or subsidy that the host country of its new investment puts in

\footnotetext{
${ }^{7}$ See the Appendix for our discussion of the quasi-linear utility function from which the inversedemand systems are derived. In the main text, this is implicitly assumed.

${ }^{8}$ We make this assumption since the trade versus FDI choice is well understood from the literature on trade costs and foreign direct investment. See, e.g. Neary (2009) for a survey. It is not the focus of our paper.

${ }^{9}$ This assumption is in line with previous contributions such as Haufler and Wooton (1999), and Bjorvatn and Eckel (2006). It should be noted that we assume off economies of scope in our analysis. If this is the case, it is easy to see that all else equal, the chance for the MNE to locate production of the new variety in the larger country will be increased.
} 
place. Each country's national welfare is the sum of the consumer surplus of its citizens together with tax revenues. Consumer surplus will rise when production takes place within the country but this may be accompanied by a fall in tax revenues if a subsidy has to be paid to attract the FDI. As the MNE is assumed to be owned by agents outside of the region, profits of the MNE are not part of either nation's welfare.

If the countries engage in fiscal competition to attract the FDI, then they and the MNE play a two-stage game of complete information in order to determine the location of the production of the new variety, good 2. In the first stage of the game, each country simultaneously and non-cooperatively announces its offer of a lump-sum subsidy $s^{i}$ to the MNE, conditional on it being chosen as host of the new FDI. ${ }^{10}$ In the second stage, after observing the offers, the MNE makes its location choice for its new investment, then services the regional demand from that country. Table 1 summarises the stages of the game.

\begin{tabular}{|c|l|}
\hline & Sequence of moves \\
\hline Stage 1 & $A$ and $B$ announce offers to attract the new FDI. \\
\hline Stage 2 & Firm chooses its location, invests, produces and sells in both countries. \\
\hline
\end{tabular}

We introduce the following notation to represent the locations of the production of the two varieties. We have assumed that the existing variety, good 1 , is produced in country $B$, so the outcomes differ as to where the second variety, good 2 , is produced. We denote the situation when the MNE decides against supplying the new variety in the regional market as $(B, \varnothing) .(B, B)$ is the case where the MNE co-locates production in the larger country $B$, while $(B, A)$ is when the MNE makes the new investment in the smaller country $A$. The corresponding equilibrium values for the three cases are indicated by subscripts $\varnothing, B$, and $A$ for $(B, \varnothing),(B, B)$ and $(B, A)$, respectively. As usual, we solve the model by backward induction.

\section{Location choice without fiscal competition}

In this section, we analyse the MNE's location choice when countries do not engage in fiscal competition for FDI. The countries refrain from making offers to attract the

\footnotetext{
${ }^{10}$ The subsidy becomes a lump-sum tax if $s^{i}$ is strictly negative.
} 
new FDI while maintaining their existing, exogenous policies, which we assume to be the same across the two countries. This will allow us to establish the degree to which country $B$ presents a more or less attractive destination for the new FDI, as compared to country $A$. We can then examine the MNE's profit-maximizing location choice given the relative geographic advantages of the two countries.

Firstly, we determine whether or not the MNE has an incentive to introduce the new variety into the region. When the MNE decides upon $(B, \varnothing)$, where it focuses on its existing variety and foregoes the regional production and sale of the new variety, good 2 , our model replicates Haufler and Wooton (1999). In this case, it is easy to show that:

$$
\begin{gathered}
q_{1}^{A}=\frac{1-\tau}{2}, \quad q_{1}^{B}=\frac{1}{2} ; \\
p_{1}^{A}=\frac{1+\tau}{2}, \quad p_{1}^{B}=\frac{1}{2} ; \\
c s_{\varnothing}^{A}=\frac{1}{8}(1-\tau)^{2}, \quad c s_{\varnothing}^{B}=\frac{N}{8} ; \\
\pi_{\varnothing}^{*}=\frac{1}{4}\left[N+(1-\tau)^{2}\right] ;
\end{gathered}
$$

where $c s_{\varnothing}^{i}$ denotes country $i$ 's consumer surplus, and $\pi_{\varnothing}^{*}$ represents the MNE's profits in the equilibrium in which a single variety is produced.

If the fixed investment cost $f$ is relatively small, then the MNE will introduce the new variety to the region because its operating profits net of the investment cost will be larger than $\pi_{\varnothing}^{*}$. When the MNE chooses to produce the new variety in country $B$, exporting both varieties to country $A$, it receives operating profits of:

$$
\begin{aligned}
\pi_{B}= & N\left[\left(1-q_{1}^{B}-b q_{2}^{B}\right) q_{1}^{B}+\left(1-b q_{1}^{B}-q_{2}^{B}\right) q_{2}^{B}\right] \\
& +\left(1-q_{1}^{A}-b q_{2}^{A}-\tau\right) q_{1}^{A}+\left(1-b q_{1}^{A}-q_{2}^{A}-\tau\right) q_{2}^{A} .
\end{aligned}
$$

It is straightforward to calculate the MNE's equilibrium sales and prices of each variety in the two markets. We have: ${ }^{11}$

$$
\begin{array}{ll}
q_{1}^{A}=q_{2}^{A}=\frac{1-\tau}{2(1+b)}, & q_{1}^{B}=q_{2}^{B}=\frac{1}{2(1+b)} ; \\
p_{1}^{A}=p_{2}^{A}=\frac{1+\tau}{2}, & p_{1}^{B}=p_{2}^{B}=\frac{1}{2} .
\end{array}
$$

\footnotetext{
${ }^{11}$ Our results on prices and quantities are in line with the results obtained in Amir et al. (2016). Given our demand structure, for monopoly firms supplying at least two goods with constant marginal cost, the price for each good is independent of demand cross-effects (the parameter $b$ in our model), and the number and characteristics of other goods. However, equilibrium outputs do depend on these relationships.
} 
Consequently, when the MNE chooses to locate the production of the new variety in country $B$, its equilibrium operating profits are:

$$
\pi_{B}^{*}=\frac{1}{2(1+b)}\left[N+(1-\tau)^{2}\right] .
$$

We note that:

$$
\frac{\pi_{B}^{*}}{\pi_{\varnothing}^{*}}=\frac{2}{(1+b)}>1
$$

The MNE has higher operating profits when it produces both varieties in country $B$ than when it produces a single variety. Therefore, if the fixed investment cost, $f$, of introducing the second variety is relatively small, then the MNE will have an incentive to manufacture both horizontally differentiated goods in the region. We henceforth assume that $f$ is sufficiently small to guarantee that the firm wishes to introduce the new variety, good 2 , to the regional market, a sufficient condition for which is that $f<\left(\pi_{B}^{*}-\pi_{\varnothing}^{*}\right) \cdot{ }^{12}$

Alternatively, the MNE could choose to produce the new variety in country $A$, exporting it to country $B$. In that case, it would receive operating profits of:

$$
\begin{aligned}
\pi_{A}= & N\left[\left(1-q_{1}^{B}-b q_{2}^{B}\right) q_{1}^{B}+\left(1-b q_{1}^{B}-q_{2}^{B}-\tau\right) q_{2}^{B}\right] \\
& +\left(1-q_{1}^{A}-b q_{2}^{A}-\tau\right) q_{1}^{A}+\left(1-b q_{1}^{A}-q_{2}^{A}\right) q_{2}^{A} .
\end{aligned}
$$

It is easy to calculate the MNE's equilibrium sales and prices of each variety in the two markets as: ${ }^{13}$

$$
\begin{aligned}
q_{1}^{A} & =\frac{(1-\tau)-b}{2\left(1-b^{2}\right)}, & q_{1}^{B} & =\frac{1-b(1-\tau)}{2\left(1-b^{2}\right)}, \\
q_{2}^{A} & =\frac{1-b(1-\tau)}{2\left(1-b^{2}\right)}, & q_{2}^{B} & =\frac{(1-\tau)-b}{2\left(1-b^{2}\right)} \\
p_{1}^{A} & =\frac{1+\tau}{2}, & p_{1}^{B} & =\frac{1}{2} \\
p_{2}^{A} & =\frac{1}{2}, & p_{2}^{B} & =\frac{1+\tau}{2} .
\end{aligned}
$$

\footnotetext{
${ }^{12}$ Obviously, it will be less interesting when the fixed investment costs are so high that the MNE's net profits from manufacturing the new variety are less than its profits when it only sells the existing variety.

It may be argued that, compared with the case where the two countries do not engage in FDI competition, the competition may provide the MNE with a sufficient incentive to make the new investment. This may be true. But it should be noted that the fixed investment cost and the scale effect associated with it are not the focus of this paper.
}

${ }^{13}$ Again, the results are in line with those obtained in Amir et al. (2016). 
Our assumption that $\tau<(1-b)$, ensures that both $q_{1}^{A}>0$ and $q_{2}^{B}>0$. From these expressions, we can determine that the equilibrium operating profits of the MNE, when it chooses to locate the production of the new variety in country $A$, will be:

$$
\pi_{A}^{*}=\frac{(N+1)}{4\left(1-b^{2}\right)}\left[1+(1-\tau)^{2}-2 b(1-\tau)\right] .
$$

We are now able to determine the MNE's location choice for its new investment when the two countries do not engage in fiscal competition for the new FDI. Expressions (3) and (5), provide a measure of country $B$ 's geographic advantage, the difference in the MNE's profit from locating its new investment in country $B$ rather than in country $A$, where:

$$
\Delta \pi \equiv \pi_{B}^{*}-\pi_{A}^{*}=\frac{\tau}{4\left(1-b^{2}\right)}[(N-1)(2-\tau)-2 b(N-1+\tau)] .
$$

At one extreme, when the two countries are the same size $(N=1)$ and given the existence of intra-regional trade costs, $\Delta \pi$ and the consequent FDI location choice are entirely driven by the degree of product differentiation between the two varieties. In short, as consumers in country $B$ have an access to domestic production of the first variety, profit maximization will require the firm to locate the new investment in country $A$ in order to reduce its trade costs of supplying an identically sized market. When $b$ is close to unity (while $\tau$ is relatively small), then the similarity in the varieties may be sufficient that each national market is served exclusively by its domestic production facility and no trade takes place. This outcome is similar to trade-cost jumping, horizontal FDI. Lower values of $b$ would result in consumers in each market wanting to consume both varieties, resulting in trade but the second variety would continue to be produced in country $A$. Only when the varieties are completely distinct from each other $(b=0)$, would the profit difference disappear such that the firm would not care about the location of the second variety.

As $N$ increases, giving country $B$ a larger population than that of country $A$, then all else equal country $B$ becomes the relatively more attractive host for the new FDI, except in the limiting case of $b=1$, where the production of a second, identical variety is only justifiable in country $A$. As the products become more differentiated, the firm's incentive to locate the production of both varieties in the larger market becomes stronger, such that when $b=0$, the varieties are distinct from one another and $\Delta \pi$ is guaranteed to be positive. This latter result replicates Haufler and Wooton (1999) for 
a separate, additional product in that the market-size advantage drives the MNE to choose the larger country $B$ for its FDI. ${ }^{14}$

In summary, the MNE's location choice for its new investment is driven by the interaction between what we define as a product-differentiation effect and a market-size effect. Products are more distinctive, and hence the product-differentiation effect is stronger, the smaller is the value of $b$. As $N$ increases, the difference in the sizes of the two countries becomes more pronounced, strengthening the market-size effect. The stronger these effects are, the more attractive the larger marketplace becomes, giving it a greater geographic advantage. Thus the interplay between $b$ and $N$, for any given level of $\tau$, determines which country is the more attractive location for the production of the second variety of the product. It is useful to define a critical level of product differentiation, $b^{*}$, a function of $N$ (and $\tau$ ) such that the two effects exactly offset one another, where:

$$
b^{*} \equiv \frac{(N-1)(2-\tau)}{2[N-(1-\tau)]}
$$

We can then summarize our discussion in the following Proposition.

Proposition 1 When countries do not engage in FDI competition, the MNE will locate its new investment in the smaller country $A$ if and only if $b>b^{*}$; otherwise it will produce the new variety in the larger country $B .^{15}$

Proof See expression (6). Setting $\Delta \pi=0$ immediately implies the Proposition.

We discuss this result with the help of Figure 1. The horizontal axis measures $N$, the market size of country $B$ relative to that of country $A$, while the vertical axis measures the degree of product differentiation, $b$. The curve represents the $b^{*}$ threshold determined by expression (7). When parameter configurations lie to the left of the curve, the MNE locates production of the new variety in country $A$, otherwise the MNE makes investment in country $B$. It is easy to see that the vertical axis is in the region where the MNE chooses to invest in country $A$. As $N \longrightarrow 1$, country $B$ 's market-size advantage diminishes and the product-differentiation effect drives the MNE to produce the new variety in country $A$. It is also straightforward to see that the horizontal axis is in the region where the MNE produces the new variety in country $B$. As $b \longrightarrow 0$,

\footnotetext{
${ }^{14}$ It is easy to see that, when $\tau=0, \Delta \pi=0$, and the location choice is irrelevant.

${ }^{15}$ We therefore omit the knife-edge cases.
} 


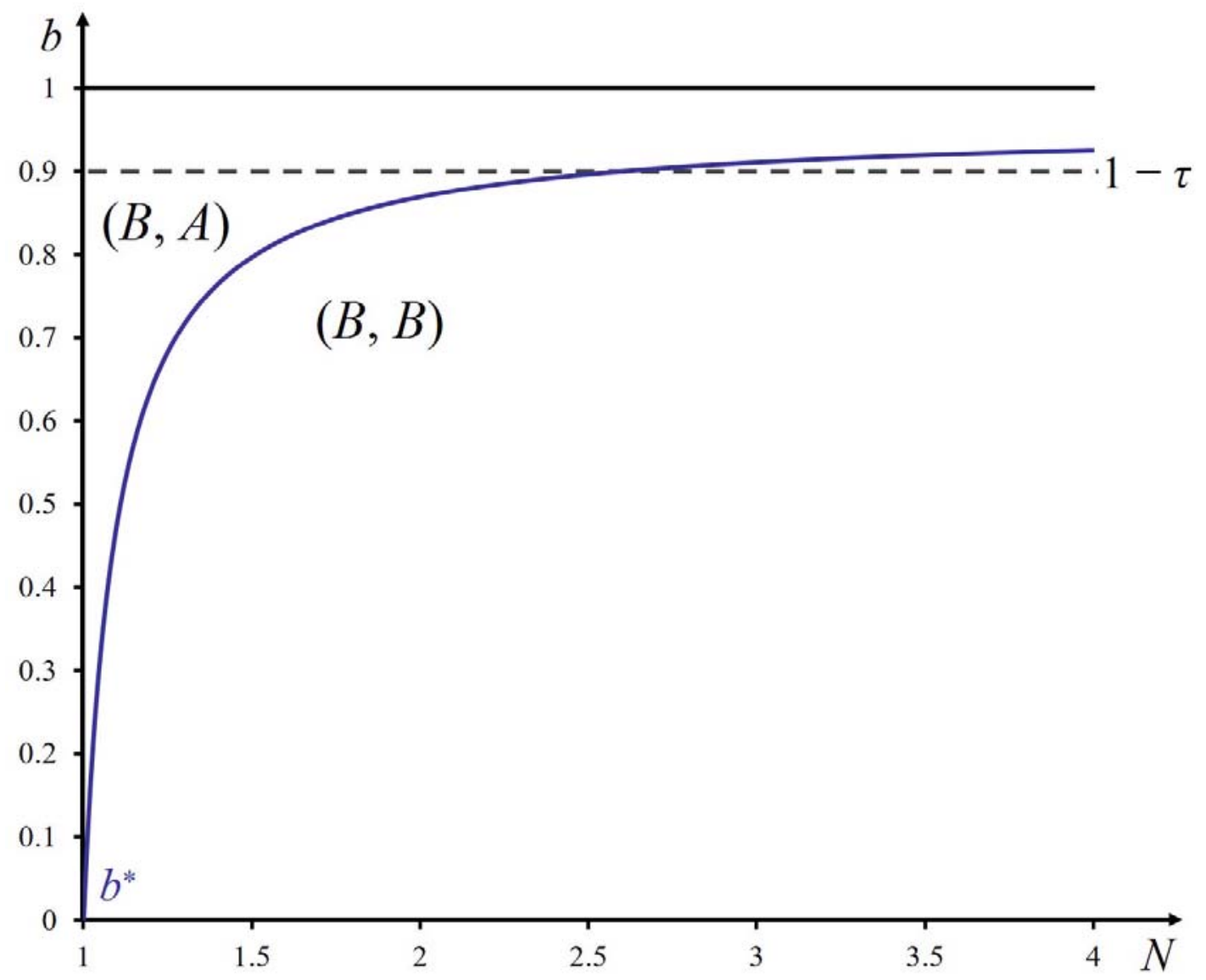

Figure 1: Location of the second variety in absence of policy competition 
the MNE's existing and new varieties become distinct goods. Hence, the market-size effect drives the MNE to locate the production of its new variety in country $B$.

Our result differs from that of Bjorvatn and Eckel (2006), where the FDI location choice is determined by the interaction between the market-size effect and the competition generated by two firms producing in the market. In contrast, we have no inter-firm competition as the second variety is produced by the same firm. In our model, when the MNE makes the new investment in country $B$, it enjoys the market-size advantage of the larger country. The firm may be "cannibalizing" its own market but, as it produces both varieties, it maximizes industry profits, whereas the new (foreign) product in Bjorvatn and Eckel (2006) directly competes with that of the incumbent local firm.

\section{Fiscal competition for FDI}

We now examine the two countries' incentives to subsidize the MNE's FDI. Consumer welfare was irrelevant to the location choice of the MNE in the previous section, as the firm made its decision purely on the basis of its profitability. But the FDI location choice has an impact on consumers. The price faced in a market reflects the cost of market access, such consumers prefer local production to imports. The national levels of consumer surplus when a second variety is introduced are:

$$
\begin{aligned}
c s_{A}^{A}=\frac{\tau^{2}+2(1-\tau)(1-b)}{8\left(1-b^{2}\right)}, & c s_{A}^{B}=\frac{N\left[\tau^{2}+2(1-\tau)(1-b)\right]}{8\left(1-b^{2}\right)} ; \\
c s_{B}^{A}=\frac{(1-\tau)^{2}}{4(1+b)}, & c s_{B}^{B}=\frac{N}{4(1+b)}
\end{aligned}
$$

where $c s_{l}^{i}$ is the consumer surplus in country $i$ when the second variety is produced in country $l, i, l \in\{A, B\} .^{16}$

When we compare the terms in expression (8) with consumer surplus in countries with a single variety, expression (2), it is clear that consumers in both nations benefit from the introduction of the second variety. Beyond that, citizens of both countries will generally gain more from the FDI for the second variety taking place in their own country than in the other nation. We see this by comparing the benefits of being the

\footnotetext{
${ }^{16}$ Appendix 1 discuss the derivation of consumer surplus from a representative consumer's quasilinear utility function.
} 
host to production of the second variety to importing it, defining the net benefits to the countries from attracting the FDI as:

$$
\begin{aligned}
\Delta W^{A} & \equiv c s_{A}^{A}-c s_{B}^{A}=\frac{\tau}{8\left(1-b^{2}\right)}[2-\tau-2 b(1-\tau)], \\
\Delta W^{B} & \equiv c s_{B}^{B}-c s_{A}^{B}=\frac{N \tau}{8\left(1-b^{2}\right)}[2-\tau-2 b] .
\end{aligned}
$$

Our maintained assumption that $\tau<(1-b)$ is a sufficient condition for $\Delta W^{i}>0$ for both countries, $i \in\{A, B\}$. Each country benefits from hosting the production of the new variety, as the prices of locally produced goods are lower than those of the imports, resulting in greater consumption surplus under FDI. Consequently, countries will be prepared to compete with each other by offering subsidies as inducements to attract the FDI to their shores. We define this impetus to attract FDI to be the import-substitution effect. ${ }^{17}$ The governments of the two potential host nations set their taxes/subsidies independently and non-cooperatively in order to maximize their national social welfare. The firm then decides in which country to make its investment, after which it services the regional demands.

In the first stage of the game of competition for the new FDI, countries $A$ and $B$ will offer lump-sum subsidies (negative taxes) $s^{A}$ and $s^{B}$, respectively. In the second stage of the game, after it has observed these offers, the MNE will choose its investment location in order to maximize its after-tax profits. Therefore, it will establish a new production plant in country $A$ if and only if $\pi_{A}^{*}+s^{A}>\pi_{B}^{*}+s^{B}$. Otherwise, it will choose to produce the new variety in country $B$. Clearly, in addition to the tradeoff between the market-size and the production-differentiation effects discussed in the previous section, the MNE's location choice is now affected by the subsidies on offer from the two countries, which are directly linked to the import-substitution effect.

The Nash fiscal competition game is a slight variant of a first-price, sealed-bid auction of complete information, in which the player with the highest willingness-to-pay for the object wins it with a payment equal to the second-highest bidder's willingness-topay. In FDI competition, a country's net benefit from the new investment is simply

\footnotetext{
${ }^{17}$ There may be several other reasons to attract local production (such as reducing involuntary unemployment, attracting jobs with premium wages, or generating production externalities for local industry, etc.); while there may be also disadvantages to the FDI (such as environmental degradation). For the sake of simplicity and analytical tractability, we focus on the increase in consumer surplus associated with domestic production.
} 
its valuation of the FDI. The complication in fiscal competition models of this type is that the country with the highest valuation of the FDI may not win the MNE's new investment. The MNE may have different pre-tax profits arising from its location choice (the pre-tax geographic advantage enjoyed by one of the countries) and this has to be taken into account together with the difference in the countries' valuation of FDI. With this in mind, we can characterize the equilibrium of the first stage game. The smaller country $A$ will win the FDI competition if and only if:

$$
\Delta W^{A}>\Delta W^{B}+\Delta \pi
$$

where its winning bid is equal to:

$$
s^{A *}=\Delta W^{B}+\Delta \pi .
$$

Otherwise, the larger country $B$ will attract the MNE and its winning bid is equal to:

$$
s^{B *}=\Delta W^{A}-\Delta \pi .
$$

This leads us to the following Proposition.

Proposition 2 When the two countries compete for the MNE's new investment, the firm will choose to locate the production of the new variety in the smaller country $A$ if and only if $b>b^{*}$; otherwise it will make the new investment in the larger country $B$.

Proof Condition (11) implies the Proposition immediately.

A direct implication of this Proposition is that the international competition to attract the FDI has no impact on the MNE's location choice. Thus allocative efficiency is unaffected by the equilibrium offers made by the countries. There is a distributional impact however, in that the offers made as a result of the competition to attract the FDI will involve transfers between citizens of the winning country and the MNE. ${ }^{18}$

Given this, we now determine the direction of the equilibrium transfer. That is, we shall work out whether the winning country subsidizes the MNE or attracts the FDI despite charging a tax. ${ }^{19}$

\footnotetext{
${ }^{18}$ Since we have linear demands for differentiated products and constant marginal costs, it turns out that the difference between country $B$ 's valuation of the FDI and that of country $A, \Delta W^{B}-\Delta W^{A}$, is proportionate to the difference in the MNE's profit from locating its new investment in country $B$ rather than in country $A, \Delta \pi$. As the former is one half of the latter, we have our result.

${ }^{19}$ The MNE always has an option not to introduce the new variety into the region, in which case
} 


\subsection{The smaller country attracts the FDI}

First, we consider the case when the smaller country $A$ wins the FDI competition. In order to do so, we define a new threshold level of product differentiation:

$$
b^{* *}=\frac{(3 N-2)(2-\tau)}{2[3 N-2(1-\tau)]} .
$$

As $b^{*}<b^{* *}$, this new threshold corresponds to a level of product differentiation such that the two varieties are sufficiently similar that the FDI will take place in country $A$. The remaining question is whether the FDI is attracted in equilibrium with a subsidy or a tax. This is clarified in the following Proposition.

Proposition 3 When country A attracts the MNE's new investment, it collects a tax from the MNE if and only if $b>b^{* *}$, otherwise, it subsidizes the FDI in equilibrium.

Proof Rewriting expression (12), we find:

$$
s^{A *}=\frac{\tau[3 N-2(1-\tau)]}{4\left(1-b^{2}\right)}\left(b^{* *}-b\right) .
$$

Given that $b>b^{*}>0$, then $s^{A *}>0$ if and only if $b<b^{* *}$.

The larger country $B$ 's valuation of the FDI is strictly positive, while the difference in pre-tax profits makes the MNE prefer to invest in the smaller country $A$. When $b=b^{* *}$, these elements exactly offset one another such that country $A$ can attract the FDI with zero subsidy when country $B$ makes its best offer. When $b>b^{* *}$, the varieties are sufficiently alike that country $B$, the host of the existing variety's production facilities, is less enthusiastic about attracting production of the new variety, while investing in country $A$ becomes more profitable. As a result, country $A$ can win the competition with a tax.

\subsection{The larger country attracts the FDI}

Things are more complicated when country $B$ wins the new FDI. This happens when $b<b^{*}$, which arises when the larger market size of country $B$ and the degree of product

it earns $\pi_{\varnothing}^{*}$. Therefore, when countries have an opportunity to tax the MNE, the tax $s^{i}<0$ should also satisfy the MNE's participation constraint. When the firm locates in country $i$, this corresponds to $\left(s^{i *}+\pi_{i}^{*}\right)-\pi_{\varnothing}^{*} \geq f$. Our results do not change qualitatively. 
differentiation are such that the firm decides that it is more profitable to locate both varieties in the same country (see Propositions 1 and 2). We show now that country $B$ can attract the new investment with a tax, if the difference in market size is sufficiently great and the two varieties are sufficiently distinct from one another. First we define a new threshold value for the degree of product differentiation $b^{* * *}$ as:

$$
b^{* * *} \equiv \frac{(2 N-3)(2-\tau)}{2[2 N-3(1-\tau)]} .
$$

Given that our measure of product differentiation is defined over the unit interval, $b^{* * *}$ is restricted such that $b^{* * *} \in[0,1]$ only when $N \geq 3 / 2$. Taking into account this restriction, it can easily be shown that $b^{* * *}<b^{*}$. We can also use expression (16) to rewrite expression (13) for country $B$ 's winning bid as:

$$
s^{B *}=\frac{\tau[2 N-3(1-\tau)]}{4\left(1-b^{2}\right)}\left(b-b^{* *}\right) .
$$

We state our result in the following Proposition.

Proposition 4 Consider the case where country B wins the FDI competition.

(i) When $N>3 / 2$, country $B$ taxes the $M N E$ if and only if $b<b^{* * *}$; otherwise, it subsidizes the MNE.

(ii) When $N \leq 3 / 2$, whenever country $B$ attracts the new investment, it must pay a subsidy to the MNE in equilibrium.

\section{Proof}

(i) When $N>3 / 2$, we see from expression (17) that:

$$
\begin{aligned}
& s^{B *}<0 \text { if and only if } b<b^{* * *}<b^{*} ; \\
& s^{B *}>0 \text { if and only if } b^{* * *}<b<b^{*} .
\end{aligned}
$$

(ii) When $N=3 / 2, b^{* * *}=0$, and so $s^{B *}>0$. If the size of country $B$ fell below $N=3 / 2$, its geographic advantage from having a larger domestic market would be eroded. The firm's profits from locating in country $B$ decline as the country shrinks in size. In order to match the best offer from country $A$, country $B$ will have to increase its subsidy in order to persuade the firm to locate within its borders. Thus country $B$ will continue to attract the FDI whenever $b<b^{*}$ but the subsidy that it has to offer in equilibrium will rise as $N$ falls. 
Country A's valuation of the FDI is strictly positive, while the MNE has an incentive to locate production of the new variety in country $B$ whenever the latter country offers a sufficiently large market and the two varieties are relatively distinct. When country $B$ is not much larger than country $A$ and the varieties become quite similar, then country $B$ will have to pay the MNE a subsidy in equilibrium in order to get the new investment. We now turn to an analysis of the welfare consequences of FDI competition.

\section{Welfare implications of fiscal competition}

First, we study whether fiscal competition to attract the FDI achieves allocative efficiency. We then turn to examine whether a competing country gains or loses from the FDI competition, compared with the situation where the countries do not engage in it. As noted in the previous section, the competition for FDI does not affect the FDI location choice. Indeed, it is efficient, as stated in the following Proposition.

Proposition 5 The MNE's location choice for its new investment is efficient, in that it maximizes total world welfare, regardless of whether or not there is international competition for the FDI.

Proof When $b>b^{*}$, the MNE chooses to produce the new variety in the smaller coun$\operatorname{try} A$ irrespective of whether or not the two countries engage in the FDI competition. With appropriate substitutions, condition (11) can be rewritten as $\left[c s_{A}^{A}+c s_{A}^{B}+\pi_{A}^{*}\right]-$ $\left[c s_{B}^{A}+c s_{B}^{B}+\pi_{B}^{*}\right]>0$. Similar arguments apply for the case when $b<b^{*}$, and the MNE makes the new investment in the larger country $B$.

That FDI competition achieves allocative efficiency is well known in the existing literature. We have shown that this also holds in our model, in that the subsidies or taxes in equilibrium have no impact on the firm's choice of location for the FDI.

Fiscal competition for FDI will, however, affect the international distribution of the benefits of economic activity. As the fiscal competition does not affect the location of the FDI, the "losing" country is unaffected in equilibrium. Fiscal competition results in a redistribution of rents between the firm and the "winning" country. We have already established the thresholds that determine which country wins and whether it does so with a tax or a subsidy. If the firm making the investment has its ownership in the rest 
of the world (that is, in neither country $A$ nor country $B$ ), then an equilibrium tax will increase regional welfare while a subsidy will reduce it.

As we noted in the above analysis, all else equal, the larger market size of country $B$ relative to that of country $A$ gives an edge to country $B$, while close similarity in the varieties (a low degree of product differentiation) can put country $A$ in a more advantageous position in attracting the MNE's new investment. The larger a country's geographic advantage, the greater its ability to tax the FDI in equilibrium. If the winning country's edge over its rival is insufficiently large, then it needs to subsidize the FDI in equilibrium. However, if the winning country's advantage is great enough, then it can tax the firm while capturing the FDI. ${ }^{20}$

Figure 2 adds the two additional thresholds, $b^{* *}$ and $b^{* * *}$, to the previous diagram in order to illustrate the tax/subsidy implications of policy competition. The original $b^{*}$ curve is unchanged, since we have established that policy competition does not affect the MNE's location choice, but merely affects the after-tax earnings of the firm and the rents accrued by the host nation.

The curve marked $b^{* *}$ corresponds to expression (14). When parameter configurations are above the curve, country $A$ taxes the MNE, and competition for FDI Pareto-weakly improves national welfare of the competing countries. When parameter configurations are between the $b^{*}$ and $b^{* *}$ curves, country $A$ subsidizes FDI, and competition for FDI Pareto-weakly reduces national welfare of the competing countries. The curve marked $b^{* * *}$ is the threshold given by expression (16). When parameter configurations are below this curve, country $B$ taxes the MNE and FDI competition Pareto-weakly enhances national welfare of the competing countries. When parameter configurations are between the $b^{*}$ and $b^{* * *}$ curves, country $B$ subsidizes the MNE and FDI competition Pareto weakly reduces national welfare of the competing countries. Therefore, when parameter configurations are close to the $b^{*}$ curve, meaning that no country has an overwhelming geographic advantage, the winning country needs to pay a subsidy to the MNE in order to offset the subsidy offer made by its rival. When the winning

\footnotetext{
${ }^{20}$ That fiscal competition for FDI may Pareto weakly improve national welfare of the competing countries seems to be interesting, and this result is in line with Ma (2013). Bjorvatn and Eckel (2006) obtain a similar result. That happens when one of the competing countries does not benefit from the entry of the MNE; and hence, its valuation of FDI is strictly negative. This increases the bargaining power of the other country and may lead to taxation of FDI rather than subsidies. In contrast, we derive the result in the situation where both countries have an economic incentive to attract FDI.
} 


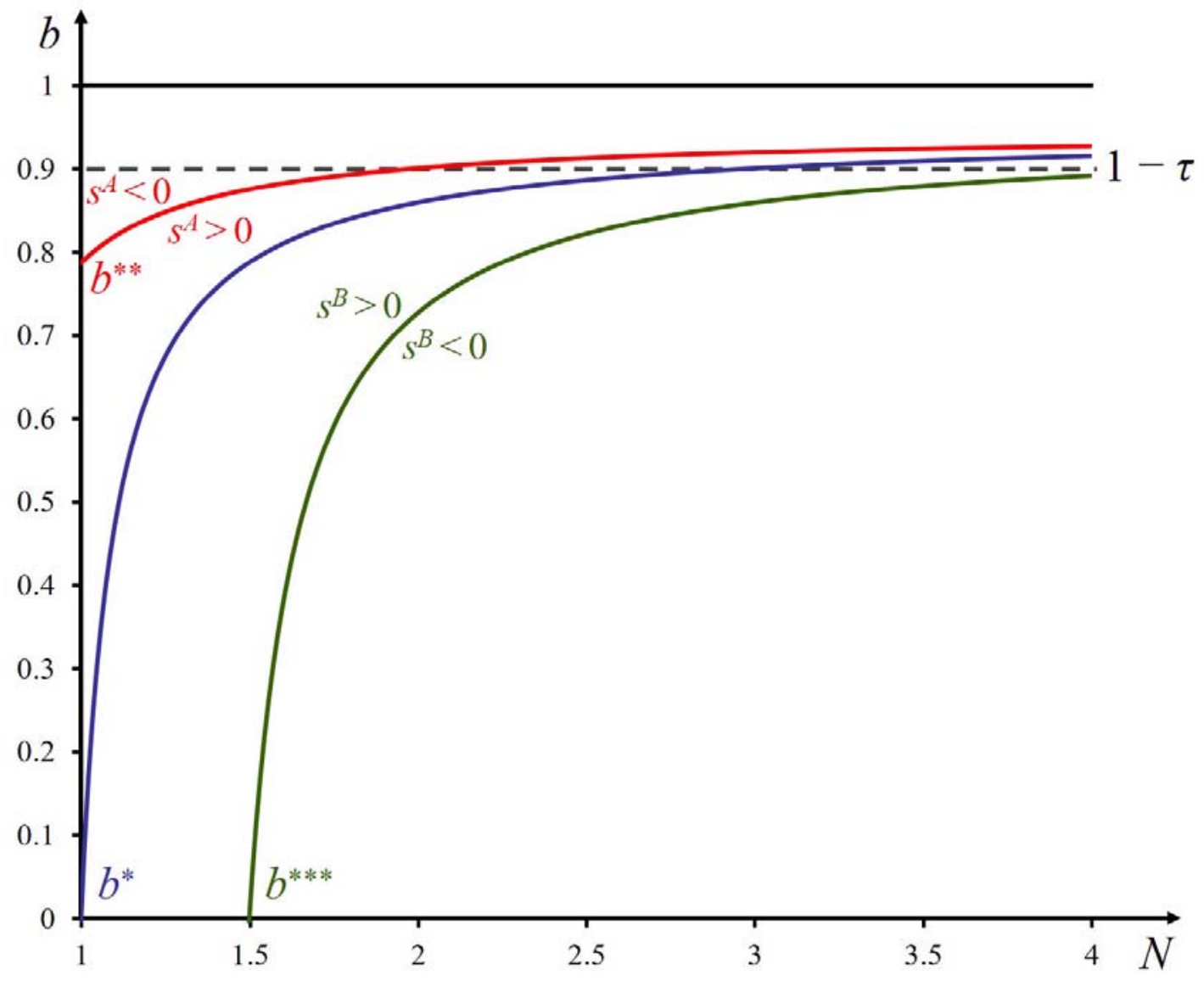

Figure 2: Corporate taxes or subsidies in equilibrium 
country has a sufficiently strong geographic advantage relative to its rival, reflected in parameter configurations far from the $b^{*}$ curve, then the winning country can attract the FDI while taxing the MNE.

Moving horizontally across the Figure 2 reveals the full range of possible outcomes as $N$ increases while $b$ remains constant, starting from the initial intersection with the vertical axis where $N=1$. When the two countries are the same size, the FDI will take place in country $A$. This is because that the firm will wish to separate spatially its two plants that are producing horizontally differentiated goods. When the two goods are sufficiently similar, the host country is able to tax the firm. As the size of country $B$ relative to that of country $A$ starts to increase, country $A$ becomes a less attractive destination and will have to subsidize the firm in order to capture the FDI. Eventually as $N$ increases, country $A$ 's subsidy will be insufficient to win the FDI and country $B$ 's subsidy will, instead, attract the new investment. With a sufficiently large asymmetry in country size, the second variety will, in equilibrium, be produced in country $B$ despite the fact that the firm is taxed for locating there.

In a similar fashion, we can analyse the outcomes for a given size differential between the two countries but for different degrees of substitutability between the two varieties as we move vertically up across the Figure 2 . When the two goods are completely distinct $(b=0)$, the production of both will be located in the larger country. If $N$ is sufficiently large, country $B$ taxes the FDI in equilibrium. As $b$ rises, country $A$ becomes a more attractive location for production of the second variety, such that the tax/subsidy and location outcomes change accordingly.

\section{Summary and extensions}

In our model, an MNE chooses the location of its new manufacturing facility in a region in which it already produces a horizontally differentiated variety of the good. We have considered how this choice is affected by the introduction of investment incentives by the governments of the potential host nations, where we have focused on the implications for domestic welfare and the firm's after-tax profits of this international competition to attract the FDI. We show that product differentiation can affect the FDI location choice, investment policy and national welfare in interesting ways. The existing literature has addressed the interplay between market-size and import- 
substitution effects but, as far as we know, the product-differentiation effect that we have introduced is new to studies of tax competition with imperfectly competitive markets. In Appendix 2, we determine that introducing international differences in consumers' perceptions of product differentiation will not change the results of the basic model.

In our model, FDI competition does not affect the MNE's location choice. That may be mainly because we consider policy instruments that do not affect the MNE's output decisions. Regardless of whether the corporation tax that it faces is charged on a lump-sum basis or proportional to its profits, the firm's optimal output will maximise its pre-tax profits. In contrast, the MNE's location choice might change if the fiscal instrument affected its choice of output levels. Thus a production tax would change the marginal cost of producing in the country and consequently result in a change in the optimal output level. Equally, tariffs and export taxes would jointly affect output levels and the MNE's location choice when countries compete to attract the FDI. Some elements of this are examined in Appendix 3.

The degree of product differentiation between the two varieties is exogenously given in our model. If we were to extend the model to allow product differentiation to be an endogenous choice of the firm, we can determine that the costly choice of product differentiation can have far-reaching effects with respect to both the location of the production of the second variety and the tax/subsidy that it will face. ${ }^{21}$

We can also consider the scenario under which the two varieties are produced by two competing firms, in order to understand how market structure influences the outcome of fiscal competition with differentiated products. In such a setting, the circumstances under which the smaller country becomes the host to the new variety are reduced, regardless of whether there is fiscal competition for FDI or not. ${ }^{22}$

Finally, a challenging task would be to combine the basic idea of this paper and that of Ferrett and Wooton (2010) to study tax competition for several heterogeneous firms in the context of imperfect competition. We hope to report results of such a study in the near future.

\footnotetext{
${ }^{21}$ Further details can be found in our discussion paper, Ma and Wooton (2019).

${ }^{22} \mathrm{Ma}$ and Wooton (2019) provides further details.
} 


\section{References}

Amir, Rabah, Jim Y. Jin, Gerald Pech, and Michael Tröge (2016), "Prices and deadweight loss in multiproduct monopoly," Journal of Public Economic Theory 18, 346-362.

Baldwin, Richard E., and Gianmarco Ottaviano (2001), "Multiproduct multinationals and reciprocal FDI dumping," Journal of International Economics 54, 429-448.

Barba Navaretti, Giorgio, and Anthony J. Venables (2004), Multinational Firms in the World Economy. Princeton: Princeton University Press.

Barros, Pedro P., and Luís Cabral (2000), "Competing for foreign direct investment," Review of International Economics 8, 360-71.

Bjorvatn, Kjetil, and Carsten Eckel (2006), "Policy competition for foreign direct investment between asymmetric countries," European Economic Review 50, 18911907.

Brander, James A., and Paul Krugman (1983), "A 'reciprocal dumping' model of international trade," Journal of International Economics 15, 313-321.

Charlton, Andrew (2003), "Incentive bidding for mobile investment: economic consequences and potential responses," OECD Development Centre Working Papers, No. 203.

Ferrett, Ben, and Ian Wooton (2010), "Competing for a duopoly: international trade and tax competition," Canadian Journal of Economics 47, 776-794.

Fumagalli, Chiara (2003), "On the welfare effects of competition for foreign direct investments," European Economic Review 47, 963-83.

Haufler, Andreas, and Ian Wooton (1999), "Tax competition for foreign direct investment," Journal of Public Economics 71, 121-139.

Ma, Jie (2013), "Market size, local sourcing and policy competition for foreign direct investment," Review of International Economics 21, 984-995.

Ma, Jie (2017), "Double-edged incentive competition for foreign direct investment," International Tax and Public Finance 24, 282-312. 
Ma, Jie, and Ian Wooton (2019), "Market size, product differentiation and bidding for new varieties," Department of Economics, University of Strathclyde Discussion Paper, No. 19-02.

Neary, J. Peter (2009), "Trade costs and foreign direct investment," International Review of Economics and Finance 18, 207-218.

Oman, Charles P. (2000), Policy Competition for FDI: A Study of Competition among Governments to Attract FDI. Paris: OECD Development Centre.

UNCTAD (1996), Incentives and FDI. New York: United Nations.

UNCTAD (2012), World Investment Report 2012: Towards a New Generation of Investment Policies. New York: United Nations.

UNCTAD (2015), World Investment Report 2015: Reforming International Investment Governance. New York: United Nations. 


\section{Appendix 1}

We discuss here the quasi-linear utility function from which inverse demand systems are derived and we show how we calculate countries' consumer surplus when the MNE introduces the new variety into the region. We implicitly assume that the representative agent in each country $i$ has a quasi-linear preference of the form:

$$
U^{i}=\left\{\begin{array}{ll}
q_{1}^{i}-\frac{1}{2} q_{1}^{i 2}+m & \text { (only good } 1 \text { available) } \\
\left(q_{1}^{i}+q_{2}^{i}\right)-\frac{1}{2}\left(q_{1}^{i 2}+2 b q_{1}^{i} q_{2}^{i}+q_{2}^{i 2}\right)+m & \text { (both goods } 1 \text { and } 2 \text { available) }
\end{array},\right.
$$

where $m$ is a homogenous numéraire good; $0 \leq b \leq 1$.

It is easy to confirm that the inverse demand systems when the MNE produces and sells both varieties in the region (expression (1)) are derived from maximising $U^{i}=$ $\left(q_{1}^{i}+q_{2}^{i}\right)-\frac{1}{2}\left(q_{1}^{i 2}+2 b q_{1}^{i} q_{2}^{i}+q_{2}^{i 2}\right)+m$ subject to the budget constraint. Each country's representative agent receives consumer surplus equal to:

$$
c s^{i}=\left(q_{1}^{i}+q_{2}^{i}\right)-\frac{1}{2}\left(q_{1}^{i 2}+2 b q_{1}^{i} q_{2}^{i}+q_{2}^{i 2}\right)-p_{1}^{i} q_{1}^{i}-p_{2}^{i} q_{2}^{i} .
$$

The smaller country $A$ has a single consumer, while the larger country $B$ has $N$ consumers. Consequently, country $B$ 's total consumption surplus is equal to $N$ times its representative agent's consumer surplus.

\section{Appendix 2: Alternative views on product differen- tiation}

Suppose that the representative consumers in each country have different perception of the substitutability of the two products produced by the firm. We argue that, as in the basic model, FDI competition does not change the MNE's location choice. Without loss of generality, we examine the case where the representative consumer in the smaller country considers the two goods to be distinct, with a production differentiation parameter $b_{S}=0$, while the representative consumer in the larger country still treats them as being substitutes, with a production differentiation parameter $b_{L}>0$.

The larger country's market remains the same as in the basic model. However, the MNE gets more profits per capita in the smaller country's market irrespective of its location choice, while the smaller country's net benefit under FDI is greater than in 
the basic model. That is because the representative consumer is now prepared to pay more for the two goods. As a result, the MNE's equilibrium profits depend upon its location choice as follows:

$$
\begin{gathered}
\pi_{B}^{* *}=\frac{N}{2(1+b)}+\frac{(1-\tau)^{2}}{2} \\
\pi_{A}^{* *}=\frac{1+(1-\tau)^{2}}{4}+\frac{N}{4\left(1-b^{2}\right)}\left[1+(1-\tau)^{2}-2 b(1-\tau)\right]
\end{gathered}
$$

and each country's net benefits under FDI become:

$$
\begin{gathered}
\Delta W^{B}=\frac{N \tau}{8\left(1-b^{2}\right)}[2-\tau-2 b] \\
\Delta W^{A}=\frac{\tau(2-\tau)}{8}
\end{gathered} .
$$

It turns out that:

$$
\pi_{A}^{* *}>\pi_{B}^{* *} \Leftrightarrow N^{* *}<\frac{(2-\tau)\left(1-b^{2}\right)}{2-\tau-2 b}
$$

and

$$
\Delta W^{A}>\Delta W^{B}+\left(\pi_{B}^{* *}-\pi_{A}^{* *}\right) \Leftrightarrow N^{* *}<\frac{(2-\tau)\left(1-b^{2}\right)}{2-\tau-2 b} .
$$

Hence, we obtain the same result as in the basic model, in that competition for FDI does not change the MNE's location choice. That is because our model has a linear demand system and constant marginal costs. As a result, in equilibrium, the difference between two country's net benefits under FDI, and the difference between two locationspecific profit levels are proportional. We doubt whether this result would change in the more general case where $b_{S} \neq b_{L} \neq 0$.

In order to overturn the result in the basic model, we may need to introduce asymmetry between the competing countries from the supply side, such as only one country having a problem of unemployment (Barros and Cabral (2000)) or where one country has a local firm competing with the FDI (Bjorvatn and Eckel (2006)).

\section{Appendix 3: The effects of a local production tax/subsidy}

Consider the case where countries compete for the investment of the MNE's new variety by subsidizing/taxing the MNE's local production of the variety. An export subsidy would never be used by a government because it may be only justified in an environment of international oligopolistic competition. 
When the MNE chooses to make investments in the larger country $B$, the operating profits it receives are:

$$
\begin{aligned}
\pi_{B}= & N\left[\left(1-q_{1}^{B}-b q_{2}^{B}-c\right) q_{1}^{B}+\left(1-b q_{1}^{B}-q_{2}^{B}-c\right) q_{2}^{B}+s_{B} q_{2}^{B}\right] \\
& +\left(1-q_{1}^{A}-b q_{2}^{A}-c-\tau\right) q_{1}^{A}+\left(1-b q_{1}^{A}-q_{2}^{A}-c-\tau\right) q_{2}^{A},
\end{aligned}
$$

where $s_{B}$ is country $B$ 's local production tax/subsidy and $c$ is the marginal cost of producing each variety. It can be shown that:

$$
\begin{gathered}
q_{1}^{A}=q_{2}^{A}=\frac{1-c-\tau}{2(1+b)} \\
p_{1}^{A}=p_{2}^{A}=\frac{1+c+\tau}{2} ; \\
q_{1}^{B}=\frac{(1-c)-b\left(1-c+s_{B}\right)}{2\left(1-b^{2}\right)}, q_{2}^{B}=\frac{\left(1-c+s_{B}\right)-b(1-c)}{2\left(1-b^{2}\right)}, \\
p_{1}^{B}=\frac{1+c}{2}, p_{1}^{B}=\frac{1+c-s_{B}}{2} .
\end{gathered}
$$

Consequently, when the MNE chooses to locate the production of the new variety in country $B$, its equilibrium operating profits are:

$$
\begin{aligned}
\pi_{B}^{*}= & \frac{1}{4\left(1-b^{2}\right)}\left[N(1-c)^{2}+N\left(1-c+s_{B}\right)^{2}-2 b N(1-c)\left(1-c+s_{B}\right)\right] . \\
& +\frac{(1-c-\tau)^{2}}{2(1+b)} .
\end{aligned}
$$

If country $B$ chooses not to provide a local production subsidy, we have:

$$
\pi_{B}^{* *}=\frac{1}{2(1+b)}\left[N(1-c)^{2}+(1-c-\tau)^{2}\right] .
$$

Similarly, when the MNE chooses to produce the new variety in the smaller country $A$, the operating profits it receives are:

$$
\begin{aligned}
\pi_{A}= & N\left[\left(1-q_{1}^{B}-b q_{2}^{B}-c\right) q_{1}^{B}+\left(1-b q_{1}^{B}-q_{2}^{B}-c-\tau\right) q_{2}^{B}\right] \\
& +\left(1-q_{1}^{A}-b q_{2}^{A}-c-\tau\right) q_{1}^{A}+\left(1-b q_{1}^{A}-q_{2}^{A}-c\right) q_{2}^{A}+s_{A} q_{2}^{A},
\end{aligned}
$$

where $s_{A}$ is country $A$ 's local production tax/subsidy and $c$ is the marginal cost of producing each variety. It can be shown that:

$$
\begin{gathered}
q_{1}^{A}=\frac{(1-c-\tau)-b\left(1-c+s_{A}\right)}{2\left(1-b^{2}\right)}, q_{2}^{A}=\frac{\left(1-c+s_{A}\right)-b(1-c-\tau)}{2\left(1-b^{2}\right)} \\
p_{1}^{A}=\frac{1+c+\tau}{2}, p_{2}^{A}=\frac{1+c-s_{A}}{2} ; \\
q_{1}^{B}=\frac{(1-c)-b(1-c-\tau)}{2\left(1-b^{2}\right)}, q_{2}^{B}=\frac{(1-c-\tau)-b(1-c)}{2\left(1-b^{2}\right)} \\
p_{1}^{B}=\frac{1+c}{2}, p_{1}^{B}=\frac{1+c+\tau}{2} .
\end{gathered}
$$


Consequently, when the MNE chooses to locate the production of the new variety in country $A$, its equilibrium operating profits are:

$$
\begin{aligned}
\pi_{A}^{*}= & \frac{1}{4\left(1-b^{2}\right)}\left[N(1-c)^{2}+N(1-c-\tau)^{2}-2 b N(1-c)(1-c-\tau)\right] \\
& +\frac{1}{4\left(1-b^{2}\right)}\left[(1-c-\tau)^{2}+\left(1-c+s_{A}\right)^{2}-2 b(1-c-\tau)\left(1-c+s_{A}\right)\right] .
\end{aligned}
$$

If country $A$ chooses not to offer a local production subsidy, we have:

$$
\pi_{A}^{* *}=\frac{(N+1)}{4\left(1-b^{2}\right)}\left[(1-c)^{2}+(1-c-\tau)^{2}-2 b(1-c)(1-c-\tau)\right] .
$$

It is clear from the above that, when both countries do not engage in FDI competition, the MNE will choose to invest in the smaller country if and only if

$$
\pi_{A}^{* *}>\pi_{B}^{* *} \Longleftrightarrow b^{* *}>\frac{(N-1)(2-2 c-\tau)}{2[N(1-c)-(1-c-\tau)]}
$$

and vice versa.

It is not obvious that the necessary and sufficient condition under which $\pi_{A}^{*}>\pi_{B}^{*}$ coincides with condition (A3.1) above. As a result, policy competition may change the FDI location choice when the policy instrument used affects the MNE's marginal decisions. 